\title{
Cerebrospinal Fluid Biomarkers in Clinical Subtypes of Early-Onset Alzheimer's Disease
}

\author{
Edmond Tenga, c Tritia R. Yamasaki ${ }^{a}$ Michelle Tran ${ }^{a} \quad$ Julia J. Hsiao ${ }^{\text {a, c }}$ \\ David L. Sultzer ${ }^{a, c} \quad$ Mario F. Mendez ${ }^{a-c}$ \\ Departments of a Neurology and ${ }^{b}$ Psychiatry and Biobehavioral Sciences, David Geffen \\ School of Medicine, University of California, and ' $V$ eterans Affairs Greater Los Angeles \\ Healthcare System, Los Angeles, Calif., USA
}

\section{Key Words}

Early-onset Alzheimer's disease · Logopenic progressive aphasia · Posterior cortical atrophy $\cdot$ Cerebrospinal fluid $\cdot$ Biological markers $\cdot$ Amyloid $\cdot$ Tau

\begin{abstract}
Background/Aims: Accurate diagnosis of sporadic early-onset Alzheimer's disease (EOAD) can be challenging, and cerebrospinal fluid (CSF) biomarkers may assist in this process. We compared CSF indices between three EOAD subtypes: amnestic, logopenic progressive aphasia (LPA), and posterior cortical atrophy (PCA). Methods: We identified 21 amnestic EOAD, 20 LPA, and 12 PCA patients with CSF data, which included amyloid $\beta_{1-42}(A \beta 42)$, total tau (t-tau), phospho-tau ${ }_{181}$ (p-tau), and A $442 / t$-tau index (ATI) levels. Results: A 342 and ATI levels were similar across groups, but t-tau and $p$-tau levels were significantly lower in PCA patients. Conclusions: The A 442 and ATI data confirm the commonality of the A $\beta$ pathology in EOAD. The lower tau indices in PCA patients may reflect differences in the distribution of neurofibrillary tangles or rates of neurodegeneration.

(C) 2013 S. Karger AG, Basel
\end{abstract}

\section{Introduction}

Sporadic early-onset Alzheimer's disease (EOAD; age $\leq 65)$ is more heterogeneous than late-onset Alzheimer's disease (LOAD; age $>65$ ). EOAD is comprised of a number of nonamnestic variants whose most prominent presenting symptoms are disturbances in language, visuospatial skills, praxis, or executive functions [1]. The proportion of EOAD that presents 
Teng et al.: Cerebrospinal Fluid Biomarkers in Clinical Subtypes of Early-Onset Alzheimer's Disease

with nonamnestic symptoms ranges from 22 to $64 \%$, and the most common clinical subtypes are logopenic progressive aphasia (LPA) and posterior cortical atrophy (PCA) [2]. These subtypes of EOAD differ from typical amnestic LOAD not only in clinical presentation [3-6], but also in a more aggressive course [7], the absence of an association with the presence of an apolipoprotein E $\varepsilon 4$ allele $[6,8]$, and distinct patterns of early neuropathological changes [9].

Nonamnestic presentations of Alzheimer's disease (AD) have been included in the current diagnostic criteria for $\mathrm{AD}$ [10], and specific diagnostic criteria have been developed for both LPA [11] and PCA $[12,13]$. However, accurate diagnosis of patients with nonamnestic EOAD variants remains difficult. This is particularly unfortunate, because while AD devastates at any age, the prompt diagnosis and mobilization of resources is absolutely vital when it affects those in their most productive years who have continuing financial and familial obligations [14].

Given the challenges of diagnosing AD based solely on clinical features, recent diagnostic criteria have incorporated the use of biomarker data [10], including cerebrospinal fluid (CSF) measurements of amyloid $\beta_{1-42}(\mathrm{~A} \beta 42)$, total tau ( $\mathrm{t}$-tau), and phosphorylated tau (p-tau). Several prior studies have compared CSF biomarkers between amnestic EOAD and PCA, and most have reported similar results between these subgroups [15-19]. However, one study found that $p$-tau levels and t-tau/A 342 and $p$-tau/A $\beta 42$ ratios were significantly lower in PCA than amnestic EOAD [20]. A number of smaller studies have compared CSF biomarkers in LPA to diagnostic thresholds established for LOAD and indicated that the majority of LPA patients have CSF biomarkers levels in the LOAD range [21-24]. However, it remains unclear whether CSF biomarker levels differ between EOAD and LOAD [25-27], and the aforementioned studies did not directly compare CSF biomarkers between patients with amnestic EOAD and LPA. The current study aims to clarify the value of CSF biomarkers for distinguishing clinical variants of EOAD by analyzing CSF A $\beta 42$, t-tau, and p-tau levels across EOAD patients with amnestic, LPA, and PCA presentations.

\section{Methods}

\section{Participants}

We performed a retrospective chart review of patients who presented to the Neurobehavior Clinic at the David Geffen School of Medicine, University of California, Los Angeles (UCLA), Calif., USA, for evaluation between 2002 and 2013. We identified 53 patients with an initial onset of cognitive symptoms before the age of 65 years who lacked a family history of early-onset dementia among first-degree relatives, fulfilled diagnostic criteria for probable amnestic AD $(n=21)$ [28], LPA $(n=20)$ [11], or PCA $(n=12)$ [12], and had CSF biomarker data documented in their medical records. There were fewer patients in the PCA group than in the other EOAD groups because CSF analyses for PCA patients were only prioritized during the latter portion of the interval selected for chart review. Therefore, we also compared the clinical features of the PCA patients with CSF data to a separate cohort of 27 PCA patients without CSF data that were seen in the same clinic and were described in a prior report [29]. These analyses were performed to determine whether the smaller subset of PCA patients with CSF data were representative of the larger population of PCA patients seen in our clinic. This retrospective review of patient records was approved by the UCLA Institutional Review Board.

\section{Clinical Evaluation}

All patients underwent a clinical assessment that included: clinical history, Mini-Mental State Examination (MMSE) [30], neurological examination, ophthalmological examination [near and distant (Snellen) visual acuity, basic color vision, visual field testing by confrontation, ophthalmoscopy, pursuit eye movements, and saccades to command and visual stimuli], routine laboratory tests (complete blood count, chemistries, VDRL, and thyroid function tests), and structural neuroimaging (either computed tomography or magnetic resonance imaging scans of the brain). A subset of patients also received fluorodeoxyglucose (FDG) positron emission tomography (PET) scans of the brain. FDG-PET scans were reviewed by a blinded experi- 
Teng et al.: Cerebrospinal Fluid Biomarkers in Clinical Subtypes of Early-Onset Alzheimer's Disease

Table 1. Demographics of the EOAD patients with CSF biomarker data

\begin{tabular}{lcccl}
\hline & Amnestic $(\mathrm{n}=21)$ & LPA $(\mathrm{n}=20)$ & PCA $(\mathrm{n}=12)$ & $\mathrm{F}(2,50) / \chi^{2}(2,53)$ \\
\hline Male gender, \% & 52.4 & 40.0 & 50.0 & 2.32 \\
Age at symptom onset, years & $52.0(5.2)^{* *}$ & $52.6(3.3)$ & $56.1(4.6)$ & $3.53^{*}$ \\
Age at LP, years & $54.9(4.5)$ & $56.6(3.9)$ & $58.8(5.1)$ & 3.00 \\
Disease duration at LP, years & $2.9(1.9)$ & $4.0(2.3)$ & $2.8(1.7)$ & 1.98 \\
MMSE score at LP & $21.4(6.2)$ & $17.7(7.1)$ & $19.6(6.6)$ & 1.62 \\
A $342, p g / m l$ & $329.90(134.25)$ & $306.66(132.35)$ & $258.63(50.26)$ & 1.35 \\
t-tau, pg/ml & $847.83(484.84)^{* *}$ & $818.63(512.93)^{* *}$ & $352.37(73.73)$ & $5.53^{*}$ \\
p-tau, pg/ml & $88.99(25.62)^{* *}$ & $90.85(40.62)^{* *}$ & $52.15(9.36)$ & $6.69^{\mathrm{a}},,^{*}$ \\
ATI & $0.29(0.13)$ & $0.29(0.21)$ & $0.40(0.08)$ & 1.87 \\
t-tau/p-tau ratio & $8.08(2.25)$ & $8.14(1.69)$ & $6.88(0.77)$ & $1.97^{\mathrm{a}}$ \\
\hline
\end{tabular}

Values in parentheses are standard deviations. ${ }^{*} \mathrm{p}<0.05$; ${ }^{* *} \mathrm{p}<0.05$ vs. PCA after Bonferroni correction.

${ }^{a} \mathrm{~F}(2,45)$ as p-tau data were not available for 5 patients ( 2 amnestic, 2 LPA, and 1 PCA).

enced rater (D.L.S.) who assessed hypometabolism in the temporal, parietal, and occipital lobes using a semiquantitative scale (0: none, 1: mild, 2: moderate, and 3: severe).

\section{CSF Collection and Analyses}

CSF was collected during clinical evaluations in situations where the supervising physician (M.F.M.) believed that biomarker data would assist in diagnosis and/or management, and consent was obtained for lumbar puncture (LP). CSF was collected into polypropylene test tubes, centrifuged, and frozen within $1 \mathrm{~h}$ of collection. CSF samples were shipped to Athena Diagnostics (Worcester, Mass., USA) for analyses of A $\beta 42$, t-tau, and p-tau performed using commercially available ELISA kits [INNOTEST $\beta$-amyloid (1-42), INNOTEST hTau Ag, INNOTEST p-Tau (181P); Innogenetics, Ghent, Belgium]. Clinical reports included individual CSF analyte levels and an A $\beta 42 / \mathrm{t}$-tau index [ATI, calculated as A $\beta 42 /(240+1.18 \mathrm{t}$-tau $)]$. Athena Diagnostics reports abnormal (i.e. AD range) values as ATI $<1.0$ and p-tau $>61 \mathrm{pg} / \mathrm{ml}$. Previous studies investigating CSF biomarkers in AD using the same Innogenetics ELISA kits have defined abnormal values as A $\beta 42<500$ and t-tau $>350 \mathrm{pg} / \mathrm{ml}[16,17]$.

Data Analyses

Statistical analyses were performed using SPSS 16.0 for Mac (SPSS Inc., Chicago, Ill., USA). Demographic and CSF biomarker data were compared between diagnostic groups using one-way analysis of variance or unpaired t tests for continuous variables and Kruskal-Wallis or $\chi^{2}$ tests for categorical variables. Post hoc analyses were Bonferroni corrected for multiple comparisons where appropriate.

\section{Results}

Demographics of the amnestic EOAD, LPA, and PCA patients with CSF biomarker data are shown in table 1 . The three subgroups were similar in gender distribution, disease duration at the time of LP, and MMSE scores at the time of LP. Age at symptom onset was significantly different across groups $(p=0.037)$. Bonferroni-corrected post hoc analyses indicated that the age at initial symptom onset in the PCA group was significantly later than that reported for the amnestic EOAD group ( $p=0.041)$, but was not different from the LPA group ( $p=0.103)$. There was also a trend towards a group difference in age at the time of LP ( $p=0.059)$, but individual comparisons did not survive Bonferroni correction ( $\mathrm{p}$ values $>0.05$ ).

CSF biomarker indices for the three EOAD subgroups are also shown in table 1 . A $\beta 42$ levels and ATIs were similar across all groups ( $p$ values $>0.10$ ). However, significant differ- 
Dementia

and Geriatric

Cognitive Disorders

Table 2. Percentages of EOAD patients with CSF biomarkers in the $\mathrm{AD}$ range

\begin{tabular}{l|l}
\hline \multicolumn{2}{|l}{ Dement Geriatr Cogn Disord 2014;37:307-314 } \\
\hline DOI: $\underline{10.1159 / 000355555}$ & $\begin{array}{l}\text { C) 2013 S. Karger AG, Basel } \\
\text { www.karger.com/dem }\end{array}$ \\
\hline
\end{tabular}

Teng et al.: Cerebrospinal Fluid Biomarkers in Clinical Subtypes of Early-Onset Alzheimer's Disease

\begin{tabular}{lclrc}
\hline & Amnestic & LPA & PCA & $\chi^{2}(2,53)$ \\
\hline A $\beta 42$ & $90 \%$ & $95 \%$ & $100 \%$ & 1.30 \\
t-tau & $100 \%^{* *}$ & $90 \%{ }^{* *}$ & $42 \%$ & $19.17^{*}$ \\
p-tau & $100 \%^{* *}$ & $72 \%^{* *}$ & $9 \%$ & $26.40^{\text {a }},{ }^{*}$ \\
ATI & $100 \%$ & $95 \%$ & $100 \%$ & 1.65 \\
\hline
\end{tabular}

${ }^{*} \mathrm{p}<0.05 ;{ }^{* *} \mathrm{p}<0.05$ vs. PCA after Bonferroni correction. ${ }^{\mathrm{a}} \chi^{2}(2,48)$ as p-tau data were not available for 5 patients ( 2 amnestic, 2 LPA, and 1 PCA).
Table 3. Clinical features of PCA patients with and without CSF biomarker data

\begin{tabular}{lcll}
\hline & $\begin{array}{c}\text { PCA without } \\
\text { CSF (n=27) }\end{array}$ & $\begin{array}{l}\text { PCA with } \\
\text { CSF (n=12) }\end{array}$ & $\begin{array}{l}\chi^{2}(39) / \\
\mathrm{t}(37)\end{array}$ \\
\hline Male gender, \% & 44.4 & 50.0 & 0.10 \\
Age at symptom onset, years & $59.6(5.0)$ & $56.1(4.6)$ & $2.04^{*}$ \\
Disease duration at first visit, years & $3.6(2.2)$ & $2.3(1.8)$ & 1.86 \\
MMSE score at first visit & $21.7(5.4)$ & $20.7(7.2)$ & 0.51 \\
Bálint's syndrome (any), \% & 51.9 & 33.3 & 1.15 \\
Gerstmann's syndrome (any), \% & 66.7 & 83.3 & 1.14 \\
Environmental disorientation, \% & 55.6 & 58.3 & 0.03 \\
Dressing apraxia, \% & 44.4 & 41.7 & 0.03 \\
Constructional apraxia, \% & 100 & 91.7 & 2.31 \\
Ideomotor apraxia, \% & 11.1 & 41.7 & $4.76^{*}$ \\
Prosopagnosia, \% & 3.7 & 25.0 & $4.09 *$ \\
Neglect, \% & 25.9 & 33.3 & 0.23 \\
Visual hallucinations, \% & 3.7 & 16.7 & 1.97 \\
Extrapyramidal symptoms, \% & 3.7 & 16.7 & 1.97 \\
Dystonia or myoclonus, \% & 3.7 & 16.7 & 1.97 \\
Memory symptoms, \% & 92.6 & 83.3 & 0.77 \\
Diagnosis of PCA at last visit, \% & 100 & 66.7 & $10.03^{*}$ \\
\hline
\end{tabular}

Values in parentheses are standard deviations. ${ }^{*} \mathrm{p}<0.05$.

ences between groups were seen in both t-tau $(p=0.007)$ and $p$-tau $(p=0.003)$ levels. Bonferroni-corrected post hoc analyses indicated that the PCA subgroup had significantly lower $\mathrm{t}$-tau ( $\mathrm{p}=0.010$ vs. amnestic; $\mathrm{p}=0.017$ vs. LPA) and $\mathrm{p}$-tau ( $\mathrm{p}=0.007$ vs. amnestic; $\mathrm{p}=$ 0.005 vs. LPA) levels than the other two subgroups. There were no differences in $t$-tau $/ p$-tau ratios between groups $(\mathrm{p}=0.15)$.

The percentages of EOAD patients who either met Athena Diagnostics (p-tau, ATI) or published (A 342 , t-tau [16, 17]) CSF biomarker criteria for AD are shown in table 2. There were significant differences between groups in the percentages of patients with t-tau and $\mathrm{p}$-tau levels in the AD range (both $\mathrm{p}$ values $<0.001$ ). Bonferroni-corrected post hoc MannWhitney $U$ analyses indicated that the PCA subgroup was significantly less likely than the other two EOAD subgroups to have t-tau $[\mathrm{Z}(33)=-3.88, \mathrm{p}<0.001 \mathrm{vs}$. amnestic; $\mathrm{Z}(32)=-2.90$, $\mathrm{p}=0.004$ vs. $\mathrm{LPA}]$ or $\mathrm{p}$-tau $[\mathrm{Z}(30)=-5.00, \mathrm{p}<0.001$ vs. amnestic; $\mathrm{Z}(29)=-3.24, \mathrm{p}=0.001 \mathrm{vs}$. $\mathrm{LPA}]$ levels in the AD range.

All CSF samples analyzed in this study were collected from LPs performed during the course of routine clinical care, and only a subset of the EOAD patients evaluated at the UCLA Neurobehavior Clinic have CSF biomarker data. CSF analyses have been consistently priori- 
Teng et al.: Cerebrospinal Fluid Biomarkers in Clinical Subtypes of Early-Onset Alzheimer's Disease

tized for amnestic and LPA patients, but this clinical approach was only more recently adopted for PCA patients. Therefore, we sought to determine whether the PCA patients included in the current study were representative of the larger cohort of PCA patients evaluated in our clinic over the same time period. Clinical features of PCA patients with and without CSF biomarker data are shown in table 3. PCA patients with CSF data were significantly younger at the time of symptom onset $(\mathrm{p}=0.048)$, and were marginally younger at the time of initial clinic visit ( $p=0.071)$, but both PCA cohorts had similar MMSE scores at their initial visit $(p=0.61)$. Those with CSF data were more likely to exhibit ideomotor apraxia $(p=0.029)$ or prosopagnosia $(\mathrm{p}=0.032)$ and more likely to have evolved into another diagnosis [corticobasal syndrome $(\mathrm{n}=1)$, dementia with Lewy bodies (DLB; $\mathrm{n}=2$ ), EOAD not otherwise specified $(n=1)$ ] by the last documented follow-up visit ( $p=0.002)$. Nevertheless, the small subsets of patients with and without a diagnosis of PCA at their final documented clinic visit had similar CSF biomarker levels (online suppl. table 1; for all online suppl. material, see www.karger. com/doi/10.1159/000355555). Furthermore, among the small subset of PCA patients with FDG-PET imaging available for our review, similar patterns of regional hypometabolism were seen in patients with and without CSF biomarker data (online suppl. table 2).

\section{Discussion}

Our comparisons of CSF biomarker data between clinical subtypes of EOAD indicated that patients in the amnestic, LPA, and PCA groups exhibited similarly low A $\beta 42$ and ATI levels. However, CSF t-tau and p-tau levels were lower in the PCA group than in the amnestic and LPA groups and were less likely to be in the AD range. Taken together, these findings confirm the commonality of the $\mathrm{A} \beta$ neuropathology across EOAD subtypes, but also raise the possibility that the localization and/or severity of tau neuropathology may differ across these subtypes, resulting in differential expression of tau species in the CSF.

The finding of lower CSF t-tau and p-tau levels in PCA relative to the other EOAD subtypes adds to a somewhat discordant existing literature. Although de Souza et al. [20] reported lower CSF p-tau levels in PCA relative to amnestic EOAD, most other investigators have found similar CSF tau indices in their comparisons of these subgroups [15-19]. The matter is further complicated by work from another group demonstrating that their nonamnestic EOAD cohort (which included a significant proportion of PCA patients) had significantly higher t-tau and p-tau levels than their amnestic EOAD cohort [31]. The underlying explanation for these discrepant findings remains uncertain, but there are a number of potential possibilities.

CSF tau indices may be driven not only by the type of underlying neuropathology (i.e. AD), but also by the location of neurofibrillary tangle (NFT) deposits in the brain. Prior work in patients with pathologically confirmed LOAD suggests that CSF t-tau levels correlate with NFT density in the temporal cortex, but not in other regions [32]. Although CSF p-tau levels do not appear to correlate with regional NFT density [33], they are highly correlated with CSF t-tau levels [34]. Neuropathological studies indicate that medial temporal NFT density is significantly lower in PCA relative to amnestic EOAD [13], which may explain why CSF t-tau levels were lower in our PCA patients than in our amnestic EOAD patients. In contrast, neuropathological comparisons of LPA and amnestic AD have demonstrated similar NFT densities in the entorhinal cortex [35], which is consistent with our finding of similar CSF t-tau levels in our LPA and amnestic EOAD patients.

On the contrary, differences in CSF t-tau and p-tau levels between EOAD subgroups could reflect different underlying rates of neurodegeneration, as CSF t-tau and p-tau levels may be markers of underlying neuronal cell loss [36]. By this line of reasoning, the lower CSF tau indices in the PCA cohort may be indicative of a slower neurodegenerative process, particu- 
Teng et al.: Cerebrospinal Fluid Biomarkers in Clinical Subtypes of Early-Onset Alzheimer's Disease

larly since the PCA patients were somewhat older than the patients in the other groups. However, clinical comparisons of MMSE scores or disease duration across EOAD subtypes did not show any differences in these measures. Likewise, although t-tau/p-tau ratios may be more indicative of underlying neuronal loss than individual tau indices considered in isolation [37], similar t-tau/p-tau ratios were seen across EOAD subgroups.

de Souza et al. [20] proposed that the lower CSF p-tau levels seen in their PCA cohort could be related to a greater degree of underlying neuropathological heterogeneity in PCA relative to amnestic EOAD, and around 25\% of PCA patients that undergo postmortem examinations have non-AD neuropathological diagnoses $[13,38]$. If the underlying neuropathology in our PCA patients were more heterogeneous than in our other EOAD patients, we might have expected greater variability in CSF biomarker values in this cohort. However, the converse was true, as the standard deviations for each of the CSF indices were much lower in the PCA group than in the amnestic EOAD and LPA groups (table 2). While some of our PCA patients with CSF biomarker data subsequently developed symptoms suggestive of other neurodegenerative diseases, such as corticobasal syndrome or DLB, CSF biomarker profiles for the small subsets of patients with and without a diagnosis of PCA at their last clinic visit were similar (online suppl. table 1), raising the possibility that clinical findings that emerge later in the disease course may be less indicative of an underlying pathological etiology.

Overall, our data suggest that t-tau and p-tau levels may be less consistently abnormal in EOAD than $A \beta 42$ levels or $A \beta 42 / t$-tau ratios, and support the use of the latter set of CSF biomarkers for the differential diagnosis of early-onset dementias. Previous work in LOAD suggests that CSF $A \beta 42$ and $A \beta 42 / t$-tau ratios have the greatest utility for identifying subjects with underlying $A D$ pathology [39], and our results are consistent with prior reports indicating that most (although not all) patients with a clinical diagnosis of LPA or PCA have a neuropathological diagnosis of AD $[13,35,38]$. Furthermore, the similar CSF A $\beta 42$ and ATI levels seen across subgroups in the current study and in prior studies of CSF biomarkers in amnestic EOAD and PCA [15-19] or in LPA [21-24] are consistent with the similar patterns of cortical amyloid deposition seen in these EOAD subtypes using Pittsburgh compound B-PET imaging [40]. However, A $\beta 42$ levels in isolation may have poorer discriminatory power for differentiating EOAD from DLB, since lower A $\beta 42$ levels can also be seen in DLB without concomitant increases in tau indices [41]. This is of some concern given that a proportion of clinically diagnosed PCA patients have underlying DLB pathology [13, 38].

There are a number of factors that may limit the interpretation of our results. Data were retrospectively gathered via chart review, and involved relatively small sample sizes. CSF was obtained when clinically indicated, and from only a subset of EOAD patients seen in the UCLA Neurobehavior Clinic. Therefore, there may have been a systematic bias in patients selected for CSF sampling (i.e. those who represented greater diagnostic challenges). Indeed, further chart review indicated that the PCA patients with CSF biomarker data were slightly younger, more likely to exhibit ideomotor apraxia or prosopagnosia, and more likely to receive a non-PCA diagnosis at a subsequent visit. However, the PCA patients with and without CSF biomarker data were similar on the other clinical features that were analyzed, suggesting that those with CSF biomarker data were largely representative of the larger population of PCA patients seen in our clinic. All patients were seen at a single clinic and diagnosed by the same expert clinician (M.F.M.). As such, the composition of the study cohort may have been affected by institutional referral biases and/or individual diagnostic biases.

Our findings of similar A $\beta 42$ and ATI levels, but different t-tau and p-tau levels in CSF from different clinical subtypes of EOAD highlight the potential heterogeneity of CSF biomarkers across different manifestations of $A D$ and support the use of $A \beta 42$ and ATI levels for the identification of EOAD. They further raise the possibility that CSF $t$-tau and p-tau levels may be affected by the regional expression or severity of the underlying NFT pathology. These 
Teng et al.: Cerebrospinal Fluid Biomarkers in Clinical Subtypes of Early-Onset Alzheimer's Disease

results will require further replication, through prospective studies of CSF biomarkers in larger multicenter EOAD cohorts and/or meta-analyses of CSF biomarker data from the increasing number of smaller single-center EOAD studies.

\section{Acknowledgments}

The authors would like to thank Po-Heng Tsai, Elvira Jimenez, and Michelle Mather for their assistance with data management. This work was supported by the National Institute on Aging [R01 AG034499 (to M.F.M.) and K08 AG34628 (to E.T.; jointly sponsored by the NIA, AFAR, the John A. Hartford Foundation, the Atlantic Philanthropies, the Starr Foundation, and an anonymous donor)], and a VA Merit Review (to M.F.M.).

\section{References}

1 Mendez MF, Lee AS, Joshi A, Shapira JS: Nonamnestic presentations of early-onset Alzheimer's disease. Am J Alzheimers Dis Other Demen 2012;27:413-420.

2 Mendez MF: Early-onset Alzheimer's disease: nonamnestic subtypes and type 2 AD. Arch Med Res 2012;43: 677-685.

3 Stopford CL, Snowden JS, Thompson JC, Neary D: Variability in cognitive presentation of Alzheimer's disease. Cortex 2008;44:185-195.

4 Alladi S, Xuereb J, Bak T, Nestor P, Knibb J, Patterson K, Hodges JR: Focal cortical presentations of Alzheimer's disease. Brain 2007;130:2636-2645.

5 Davidson Y, Gibbons L, Pritchard A, Hardicre J, Wren J, Stopford C, Julien C, Thompson J, Payton A, PickeringBrown SM, Pendleton N, Horan MA, Burns A, Purandare N, Lendon CL, Neary D, Snowden JS, Mann DM: Apolipoprotein E epsilon4 allele frequency and age at onset of Alzheimer's disease. Dement Geriatr Cogn Disord 2007;23:60-66.

- 6 van der Flier WM, Pijnenburg YA, Fox NC, Scheltens P: Early-onset versus late-onset Alzheimer's disease: the case of the missing ApoE epsilon4 allele. Lancet Neurol 2011;10:280-288.

- 7 Koedam EL, Pijnenburg YA, Deeg DJ, Baak MM, van der Vlies AE, Scheltens P, van der Flier WM: Early-onset dementia is associated with higher mortality. Dement Geriatr Cogn Disord 2008;26:147-152.

- 8 Schott JM, Ridha BH, Crutch SJ, Healy DG, Uphill JB, Warrington EK, Rossor MN, Fox NC: Apolipoprotein E genotype modifies the phenotype of Alzheimer disease. Arch Neurol 2006;63:155-156.

9 Murray ME, Graff-Radford NR, Ross OA, Petersen RC, Duara R, Dickson DW: Neuropathologically defined subtypes of Alzheimer's disease with distinct clinical characteristics: a retrospective study. Lancet Neurol 2011;10:785-796.

10 McKhann GM, Knopman DS, Chertkow H, Hyman BT, Jack CR Jr, Kawas CH, Klunk WE, Koroshetz WJ, Manly JJ, Mayeux R, Mohs RC, Morris JC, Rossor MN, Scheltens P, Carrillo MC, Thies B, Weintraub S, Phelps CH: The diagnosis of dementia due to Alzheimer's disease: recommendations from the National Institute on AgingAlzheimer's Association workgroups on diagnostic guidelines for Alzheimer's disease. Alzheimers Dement 2011;7:263-269.

11 Gorno-Tempini ML, Hillis AE, Weintraub S, Kertesz A, Mendez M, Cappa SF, Ogar JM, Rohrer JD, Black S, Boeve BF, Manes F, Dronkers NF, Vandenberghe R, Rascovsky K, Patterson K, Miller BL, Knopman DS, Hodges JR, Mesulam MM, Grossman M: Classification of primary progressive aphasia and its variants. Neurology 2011; 76:1006-1014

12 Mendez MF, Ghajarania M, Perryman KM: Posterior cortical atrophy: clinical characteristics and differences compared to Alzheimer's disease. Dement Geriatr Cogn Disord 2002;14:33-40.

13 Tang-Wai DF, Graff-Radford NR, Boeve BF, Dickson DW, Parisi JE, Crook R, Caselli RJ, Knopman DS, Petersen RC: Clinical, genetic, and neuropathologic characteristics of posterior cortical atrophy. Neurology 2004;63: 1168-1174.

14 Hunt DC: Young-onset dementia: a review of the literature and what it means for clinicians. J Psychosoc Nurs Ment Health Serv 2011;49:28-33.

15 Beaufils E, Dufour-Rainfray D, Hommet C, Brault F, Cottier JP, Ribeiro MJ, Mondon K, Guilloteau D: Confirmation of the amyloidogenic process in posterior cortical atrophy: value of the abeta42/abeta40 ratio. J Alzheimers Dis 2013;33:775-780.

16 Seguin J, Formaglio M, Perret-Liaudet A, Quadrio I, Tholance Y, Rouaud O, Thomas-Anterion C, Croisile B, Mollion H, Moreaud O, Salzmann M, Dorey A, Bataillard M, Coste MH, Vighetto A, Krolak-Salmon P: CSF biomarkers in posterior cortical atrophy. Neurology 2011;76:1782-1788.

17 Formaglio M, Costes N, Seguin J, Tholance Y, Le Bars D, Roullet-Solignac I, Mercier B, Krolak-Salmon P, Vighetto A: In vivo demonstration of amyloid burden in posterior cortical atrophy: a case series with PET and CSF findings. J Neurol 2011;258:1841-1851. 
Teng et al.: Cerebrospinal Fluid Biomarkers in Clinical Subtypes of Early-Onset Alzheimer's Disease

18 de Souza LC, Corlier F, Habert MO, Uspenskaya O, Maroy R, Lamari F, Chupin M, Lehericy S, Colliot O, HahnBarma V, Samri D, Dubois B, Bottlaender M, Sarazin M: Similar amyloid-beta burden in posterior cortical atrophy and Alzheimer's disease. Brain 2011;134:2036-2043.

-19 Baumann TP, Duyar H, Sollberger M, Kuhle J, Regeniter A, Gomez-Mancilla B, Schmidtke K, Monsch AU: CSF-tau and CSF-Abeta(1-42) in posterior cortical atrophy. Dement Geriatr Cogn Disord 2010;29:530-533.

$\checkmark 20$ de Souza LC, Lamari F, Belliard S, Jardel C, Houillier C, De Paz R, Dubois B, Sarazin M: Cerebrospinal fluid biomarkers in the differential diagnosis of Alzheimer's disease from other cortical dementias. J Neurol Neurosurg Psychiatry 2011;82:240-246.

-21 Hu WT, McMillan C, Libon D, Leight S, Forman M, Lee VM, Trojanowski JQ, Grossman M: Multimodal predictors for Alzheimer disease in nonfluent primary progressive aphasia. Neurology 2010;75:595-602.

22 Rohrer JD, Rossor MN, Warren JD: Syndromes of nonfluent primary progressive aphasia: a clinical and neurolinguistic analysis. Neurology 2010;75:603-610.

23 Kas A, Uspenskaya O, Lamari F, de Souza LC, Habert MO, Dubois B, Teichmann M, Sarazin M: Distinct brain perfusion pattern associated with CSF biomarkers profile in primary progressive aphasia. J Neurol Neurosurg Psychiatry 2012;83:695-698.

24 Gil-Navarro S, Llado A, Rami L, Castellvi M, Bosch B, Bargallo N, Lomena F, Rene R, Montagut N, Antonell A, Molinuevo JL, Sanchez-Valle R: Neuroimaging and biochemical markers in the three variants of primary progressive aphasia. Dement Geriatr Cogn Disord 2013;35:106-117.

-25 Andreasen N, Hesse C, Davidsson P, Minthon L, Wallin A, Winblad B, Vanderstichele H, Vanmechelen E, Blennow K: Cerebrospinal fluid beta-amyloid(1-42) in Alzheimer disease: differences between early- and late-onset Alzheimer disease and stability during the course of disease. Arch Neurol 1999;56:673-680.

-26 Iqbal K, Flory M, Khatoon S, Soininen H, Pirttila T, Lehtovirta M, Alafuzoff I, Blennow K, Andreasen N, Vanmechelen E, Grundke-Iqbal I: Subgroups of Alzheimer's disease based on cerebrospinal fluid molecular markers. Ann Neurol 2005;58:748-757.

-27 Gronning H, Rahmani A, Gyllenborg J, Dessau RB, Hogh P: Does Alzheimer's disease with early onset progress faster than with late onset? A case-control study of clinical progression and cerebrospinal fluid biomarkers. Dement Geriatr Cogn Disord 2012;33:111-117.

28 McKhann G, Drachman D, Folstein M, Katzman R, Price D, Stadlan EM: Clinical diagnosis of Alzheimer's disease: report of the NINCDS-ADRDA Work Group under the auspices of Department of Health and Human Services Task Force on Alzheimer's Disease. Neurology 1984;34:939-944.

29 Tsai PH, Teng E, Liu C, Mendez MF: Posterior cortical atrophy: evidence for discrete syndromes of early-onset Alzheimer's disease. Am J Alzheimers Dis Other Demen 2011;26:413-418.

-30 Folstein MF, Folstein SE, McHugh PR: 'Mini-mental state'. A practical method for grading the cognitive state of patients for the clinician. J Psychiatr Res 1975;12:189-198.

-31 Koric L, Felician O, Guedj E, Hubert AM, Mancini J, Boucraut J, Ceccaldi M: Could clinical profile influence CSF biomarkers in early-onset Alzheimer disease? Alzheimer Dis Assoc Disord 2010;24:278-283.

-32 Tapiola T, Overmyer M, Lehtovirta M, Helisalmi S, Ramberg J, Alafuzoff I, Riekkinen P Sr, Soininen H: The level of cerebrospinal fluid tau correlates with neurofibrillary tangles in Alzheimer's disease. Neuroreport 1997;8: 3961-3963.

-33 Buerger K, Alafuzoff I, Ewers M, Pirttila T, Zinkowski R, Hampel H: No correlation between CSF tau protein phosphorylated at threonine 181 with neocortical neurofibrillary pathology in Alzheimer's disease. Brain 2007;130:e82.

-34 Lewczuk P, Esselmann H, Bibl M, Beck G, Maler JM, Otto M, Kornhuber J, Wiltfang J: Tau protein phosphorylated at threonine 181 in CSF as a neurochemical biomarker in Alzheimer's disease: original data and review of the literature. J Mol Neurosci 2004;23:115-122.

-35 Mesulam M, Wicklund A, Johnson N, Rogalski E, Leger GC, Rademaker A, Weintraub S, Bigio EH: Alzheimer and frontotemporal pathology in subsets of primary progressive aphasia. Ann Neurol 2008;63:709-719.

-36 Hampel H, Blennow K, Shaw LM, Hoessler YC, Zetterberg H, Trojanowski JQ: Total and phosphorylated tau protein as biological markers of Alzheimer's disease. Exp Gerontol 2010;45:30-40.

-37 Kester MI, van der Vlies AE, Blankenstein MA, Pijnenburg YA, van Elk EJ, Scheltens P, van der Flier WM: CSF biomarkers predict rate of cognitive decline in Alzheimer disease. Neurology 2009;73:1353-1358.

-38 Renner JA, Burns JM, Hou CE, McKeel DW Jr, Storandt M, Morris JC: Progressive posterior cortical dysfunction: a clinicopathologic series. Neurology 2004;63:1175-1180.

-39 Shaw LM, Vanderstichele H, Knapik-Czajka M, Clark CM, Aisen PS, Petersen RC, Blennow K, Soares H, Simon A, Lewczuk P, Dean R, Siemers E, Potter W, Lee VM, Trojanowski JQ: Cerebrospinal fluid biomarker signature in Alzheimer's disease neuroimaging initiative subjects. Ann Neurol 2009;65:403-413.

-40 Lehmann M, Ghosh PM, Madison C, Laforce R Jr, Corbetta-Rastelli C, Weiner MW, Greicius MD, Seeley WW, Gorno-Tempini ML, Rosen HJ, Miller BL, Jagust WJ, Rabinovici GD: Diverging patterns of amyloid deposition and hypometabolism in clinical variants of probable Alzheimer's disease. Brain 2013;136:844-858.

-41 Hall S, Ohrfelt A, Constantinescu R, Andreasson U, Surova Y, Bostrom F, Nilsson C, Hakan W, Decraemer H, Nagga K, Minthon L, Londos E, Vanmechelen E, Holmberg B, Zetterberg H, Blennow K, Hansson O: Accuracy of a panel of 5 cerebrospinal fluid biomarkers in the differential diagnosis of patients with dementia and/or parkinsonian disorders. Arch Neurol 2012;69:1445-1452. 